\title{
CULTIVO DE EMBRIÕES EM RETROCRUZAMENTOS ENTRE TRITICUM AESTIVUM THELL. E AGROPYRON ELONGATUM HOST. \& BEAUV. ${ }^{1}$
}

\author{
DILMA CRISTINAANGRA ${ }^{2}$, MARTAMARTINS BARBOSA ${ }^{3}$, ARIANO MORAES PRESTES $^{4}$ \\ e MARIA IRENE BAGGIO DE MORAES FERNANDES
}

\begin{abstract}
RESUMO - A resistência a diversas moléstias fúngicas do trigo tem sido transferida de espécies perenes da tribo Triticeae, mas o híbrido produzido pelo cruzamento intergenérico apresenta embrião abortivo. Embora a técnica de resgate e cultivo in vitro destes embriões já seja amplamente utilizada, sua eficiência ainda é muito baixa. Este trabalho objetivou a obtenção de progênies de retrocruzamentos em híbrido F1 $(2 n=56)$, proveniente do cruzamento de trigo (Triticum aestivum) $(2 n=42)$ com Agropyron elongatum $(2 \mathrm{n}=70)$, utilizando-se a técnica de cultivo in vitro dos embriões imaturos. Partindo-se do material perene na geração $\mathrm{F} 1$, utilizou-se o trigo como parental recorrente nos retrocruzamentos. A eficiência da polinização foi de $6 \%$ no primeiro retrocruzamento (RC1) e de $12,4 \%$ no segundo (RC2). As plantas do RC1 foram viabilizadas pelo resgate e cultivo in vitro dos embriões imaturos utilizandose o meio batata-regeneração, com adição de vitaminas. De 22 sementes, 18 embriões foram resgatados e cultivados in vitro, originando 12 plântulas. Desses embriões, $50 \%$ foram normais, $27,8 \%$ apresentaram tamanho reduzido, $16,7 \%$ foram deformados e 5,5\% apresentaram desenvolvimento retardado. A eficiência do cultivo dos embriões na regeneração de plântulas foi de $66,6 \%$. Tal resultado indica que a técnica de resgate e o meio de cultura utilizados foram eficientes para o cultivo e regeneração dos embriões híbridos, obtendo progênies viáveis de retrocruzamentos a partir de híbridos intergenéricos, nas condições realizadas.
\end{abstract}

Termos para indexação: trigo, melhoramento, cruzamentos intergenéricos, resistência à doenças.

\section{EMBRYO CULTURE OF BACKCROSSES BETWEEN HYBRIDS \\ OF TRITICUM AESTIVUM THELL. AND AGROPYRON ELONGATUM HOST. \& BEAUV.}

\begin{abstract}
Resistance to fungal diseases of wheat has been transferred from perennial species of tribe Triticeae, but the hybrid so formed presents immature embryos. Although rescue and in vitro culture of these embryos has been widely utilized, its efficiency is still very low. This work aimed to obtain backcrossing progenies in hybrid $\mathrm{F} 1(2 \mathrm{n}=56)$, derived from crossing between wheat (Triticum aestivum $)(2 \mathrm{n}=42)$ and Agropyron elongatum $(2 \mathrm{n}=70)$, through in vitro culture of immature embryos. Starting from the perennial material of $\mathrm{F} 1$ generation, several backcrosses were made using wheat as the recurrent parent. Polinization efficiency was $6.0 \%$ in $\mathrm{BC} 1$ and $12.4 \%$ in $\mathrm{BC} 2$. All plants from the $\mathrm{BC} 1$ were obtained by in vitro embryo culture. The culture medium used was potato regeneration plus vitamins. From 22 seeds collected 18 embryos were cultured in vitro and gave rise to 12 plants. Fifty percent of those embryos were normal. The remaining $27.8 \%$ showed reduced size, $16.7 \%$ were deformed and $5.5 \%$ had slow growing. The efficacy of immature embryo culture was $66.6 \%$. This result indicates that rescue and culture medium techniques used were efficient for cultivation and regeneration of hybrid embryos, allowing viable backcrosses progenies from intergeneric hybrids.
\end{abstract}

Index terms: wheat, breeding, wide crosses, resistance to fungal disease.

\footnotetext{
${ }^{1}$ Aceito para publicação em 19 de maio de 1998. Extraído da dissertação de Mestrado da primeira autora, apresentada à Universidade Federal de Pelotas (UFPEL).

${ }^{2}$ Bióloga, M.Sc., CEFET-PR/UNED-PB, Caixa Postal 571, CEP 85503-390 Pato Branco, PR. E-mail: dilm@cefet.whiteduck.com.br
}

\footnotetext{
${ }^{3}$ Bióloga, M.Sc., Embrapa-Centro Nacional de Pesquisa de Trigo (CNPT), Caixa Postal 569, CEP 99001-970 Passo Fundo, RS.

${ }^{4}$ Eng. Agr., Ph.D., Embrapa-CNPT.

${ }^{5}$ Bióloga, Drạ, Embrapa-CNPT.
} 


\section{INTRODUÇÃO}

Variabilidade genética potencialmente útil ocorre naturalmente em espécies selvagens relacionadas ao trigo cultivado (Triticum aestivum) $(2 \mathrm{n}=42)$. Os gêneros Secale, Aegilops e Agropyron são espécies relacionadas ao trigo cultivado e apresentam resistência a diversas doenças e estresses abióticos (Riley $\&$ Kimber, 1966). Aproximadamente $75 \%$ das espécies da tribo Triticeae são perenes, mas podem servir como uma fonte de variabilidade genética em cruzamentos com cereais anuais, como o trigo. Resistência às ferrugens que atacam o trigo (Puccinia striiformis f. sp. tritici, P. graminis f. sp. tritici e $P$. recondita f. sp. tritici) tem sido transferida de espécies perenes com sucesso (Sharma \& Gill, 1983; Singh et al., 1993). Considerável esforço tem sido despendido com o objetivo de hibridizar trigo com espécies de Agropyron, entre essas, Agropyron elongatum $(2 \mathrm{n}=70)$, pois esse gênero faz parte do comparium do trigo, o qual compõe-se de um grupo de gêneros ligados pela capacidade de formar híbridos viáveis direta ou indiretamente (Sharma \& Gill, 1983; Mujeeb-Kazi et al., 1984). A produção de híbridos $(2 n=56)$ com hábito de crescimento perene, parcialmente férteis, torna-se particularmente interessante para estudos citogenéticos, além de ser o primeiro passo importante na introgressão de genes de espécies afins para o trigo (Jauhar, 1995).

A introdução da cultura de embriões aumentou de forma significativa as possibilidades de hibridação dentro da tribo Triticeae (Riley \& Kimber, 1966). A técnica de resgate e cultivo in vitro vem sendo amplamente utilizada em cruzamentos cujos embriões são abortivos. No entanto, muitos problemas ainda permanecem e a eficiência do resgate apresenta-se baixa ou não é descrita na literatura. Embora várias técnicas e meios de cultivo tenham sido empregados, as principais características são similares. Os embriões precisam ser resgatados no momento em que alcançam o máximo de desenvolvimento possível, no tecido materno, e antes que inicie o processo de degeneração. A excisão e transferência precisam ser realizadas sob condições assépticas, para evitar contaminação. Durante o processo de excisão, os embriões devem ser mantidos com suficiente umidade até serem transferidos para o meio de cultura, a fim de evitar danos causados pela desidratação. As particularidades dos meios de cultura podem variar dependendo da espécie em questão, mas geralmente são líquidos ou parcialmente solidificados com ágar, contendo sais minerais, uma fonte de carboidratos, vitaminas, hormônios e algumas vezes, uma fonte orgânica de N (Hadley \& Openshaw, 1980). Após a regeneração, na fase de aclimatação, a plântula precisa ajustar-se fisiologicamente, pois ao sair de um ambiente asséptico, úmido e com disponibilidade ideal de nutrientes, necessitará iniciar o processo de fotossíntese em um ambiente com baixa umidade relativa e na presença de microorganismos parasitas. A aclimatação é, sem dúvida, uma das mais difíceis etapas na obtenção de plantas adultas originadas por cultura de embriões in vitro e cultura de tecidos em geral (Grattapaglia \& Machado, 1990).

De acordo com Cauderon (1986), em cruzamentos interespecíficos naturais ou induzidos, a obtenção de um F1 ou de uma planta poliplóide não é suficiente para a criação de uma nova espécie ou variedade. Este é um trabalho que requer um profundo conhecimento da diversidade genética dos parentais,não somente em relação aos caracteres de interesse agronômico, mas também à constituição genômica e às possíveis interações com outras espécies. Além dos problemas derivados da dificuldade de pareamento entre os cromossomos homeólogos, a desarmonia entre os sistemas fisiológico e citológico das diferentes espécies, promove barreiras internas de isolamento nos vários estádios da ontogenia dos híbridos interespecíficos. A partir do conhecimento das barreiras de isolamento, para alcançar sucesso nos cruzamentos e sobrevivência do embrião híbrido, Jauhar (1993) descreveu passos essenciais que devem ser seguidos na transferência de genes afins para o trigo: identificação dos genótipos que carregam as características desejadas, os quais devem pertencer a gêneros ou espécies relacionados ao trigo, utilização das técnicas mais apropriadas tanto nos cruzamentos como no resgate dos embriões, promoção do pareamento intergenômico por meio de métodos que propiciem a homeologia entre os cromossomos parentais; realização de retrocruzamentos, utilizando-se o híbrido como planta-mãe, para recuperar a fertilidade ou, em caso de insucesso, produzir um anfiplóide pela utilização da colchicina. 
Retrocruzamentos sucessivos em trigo, seguidos de autofecundação, levam à eliminação progressiva dos cromossomos do parental doador, presentes no híbrido F1 interespecífico. Esse procedimento promove o acúmulo progressivo dos cromossomos do trigo, até a obtenção de um produto final que possuirá o complemento inteiro do trigo com alguns segmentos da espécie afim (Xueyong et al., 1992). Em cruzamentos entre uma espécie doadora resistente $\mathrm{e}$ uma variedade receptora, altamente produtiva, numerosos retrocruzamentos devem ser efetuados para restabelecer-se o balanço genômico do parental recorrente.

Este trabalho teve por objetivo obter progênies de retrocruzamentos em híbrido perene F1 (trigo PF 839197 x Agropyron elongatum PF 84001) utilizando-se a técnica de cultivo in vitro dos embriões imaturos.

\section{MATERIAL E MÉTODOS}

O estudo foi desenvolvido entre 1991 e 1994 na Embrapa-Centro Nacional de Pesquisa de Trigo (CNPT), localizada em Passo Fundo, RS. Foram utilizados híbridos perenes, em geração $\mathrm{F} 1$, obtidos por cruzamentos intergenéricos realizados em 1988 entre a cv. PF 839197 de trigo (Triticum aestivum, $2 \mathrm{n}=42$ ) e o genótipo PF 84001 de Agropyron elongatum, espécie perene $2 \mathrm{n}=70$, atualmente descrita pelo sinônimo Thinopyrum ponticum. Partindo-se do híbrido F1 (PF 839197/PF 84001), foram efetuados retrocruzamentos utilizando-se o trigo PF 839197 como parental recorrente.

As plantas utilizadas nos retrocruzamentos permaneceram em casa de vegetação, sob condições ambientais parcialmente controladas (temperatura de $20^{\circ} \mathrm{C} \pm 3^{\circ} \mathrm{C}$ ). As sementes da linhagem de trigo PF 839197 foram semeadas diretamente em baldes de plástico, com semeadura periódica semanal, objetivando o florescimento na mesma época que o híbrido F1 perene (PF 839197/PF 84001). Antes da polinização, os híbridos F1 foram emasculados. A emasculação foi realizada em espigas com órgãos reprodutivos imaturos, antes da antese, para evitar a autofecundação. Em cada espigueta, restaram duas flores laterais cujas anteras foram retiradas com o auxílio de uma pinça. Após a emasculação, as espigas foram ensacadas em envelopes de papel vegetal branco encerado, para não ocorrer polinizações indesejadas. Foram feitas observações diárias com o objetivo de verificar quando os estigmas estariam receptivos, aptos à polinização. Nesse momento efetuou-se a aplicação do pólen, coletado da planta doadora em placa-de-Petri e transferido ao ovário da planta-mãe com um pincel. Após 24 horas houve a repolinização, utilizando-se o mesmo procedimento. A eficiência da polinização foi avaliada pelo número de grãos formados a partir das flores polinizadas.

Entre 15 e 30 dias após a polinização, os grãos foram retirados da espiga, para evitar que a degeneração do endosperma causasse a morte do embrião. O processo de degeneração do endosperma caracterizou-se pelo escurecimento e murchamento externo do grão na espiga, no sentido ápice-base. O critério utilizado para determinar o momento do resgate dos embriões foi a evolução dos sintomas em um terço do comprimento do grão. A remoção do embrião foi realizada no laboratório, em câmara de fluxo laminar, com o auxílio de um microscópio estereoscópico. A assepsia superficial foi feita mergulhando-se o grão por 15 segundos em solução de hipoclorito de sódio comercial a $50 \%$ com água esterilizada, e em álcool comercial a $70 \%$, por 20 segundos. Foram feitos cortes superficiais no tegumento e no pericarpo da extremidade basal do grão, retirando-se o embrião com uma espátula. $\mathrm{O}$ embrião foi colocado no tubo de ensaio em posição ventral, com o escutelo em contato com o meio de cultura. Com o auxílio de uma espátula, ele foi hidratado com uma gota d'água esterilizada, como forma de evitar a desidratação causada pelo ressecamento no momento da excisão. $\mathrm{O}$ meio de cultura utilizado foi o Batata-Regeneração: meio de Chuang et al. (1978) modificado pela adição de vitaminas, que compõe-se de extrato aquoso de batata a $5 \%$; Fe EDTA $10 \mathrm{~mL} / \mathrm{L}$; vitamina Fuji $2 \mathrm{~mL} / \mathrm{L}$; ácido indol acético $1 \mathrm{~mL} / \mathrm{L}$; macrobatata regeneração $100 \mathrm{~mL} / \mathrm{L}$; sacarose $30 \mathrm{~g} / \mathrm{L}$ e ágar $7 \mathrm{~g} / \mathrm{L}$; o pH foi ajustado em 5,9. Autoclavouse por 15 minutos em erlenmeyer e por 25 minutos em tubos de ensaio. Os tubos contendo os embriões foram envoltos em papel alumínio, permanecendo por quatro dias na geladeira, a $4^{\circ} \mathrm{C}$. Após esse período foram incubados em câmara de crescimento, a $20^{\circ} \mathrm{C}$, no escuro, até a germinação, quando então foram expostos à iluminação, com lâmpadas Grow Lux, em fotoperíodo de 12 horas. As plântulas regeneradas permaneceram nessas condições até atingirem um bom desenvolvimento radicular. A eficiência da cultura de embriões foi avaliada pelo número de plântulas regeneradas a partir dos embriões cultivados no meio de cultura.

As plântulas cultivadas in vitro, que apresentaram bom desenvolvimento foram transferidas para vasos de plástico com vermiculita e regadas com solução nutritiva de Hoagland \& Arnon (1969). Sobre os vasos foram emborcados copos de Becker de $500 \mathrm{~mL}$ para manter umidade. Os copos foram sendo inclinados, aos poucos, até que as 
plântulas se adaptassem à nova condição ambiental. Nas primeiras 24 horas, os vasos permaneceram na câmara de crescimento, no laboratório, a $20^{\circ} \mathrm{C}$ com fotoperíodo de 12 horas. Em seguida foram levados para câmara de crescimento (fitotron), com temperatura média de $15^{\circ} \mathrm{C}$ e fotoperíodo de 10 horas de luz. Ao atingirem o estádio de perfilhamento, as plantas foram transplantadas para baldes com solo e posteriormente levadas à casa de vegetação. A eficiência da aclimatação foi avaliada pelo número de plantas que atingiram a fase adulta, em casa de vegetação, desenvolvidas a partir das plântulas regeneradas em tubo de ensaio.

A partir do RC2 não houve a necessidade do resgate dos embriões, os grãos permaneceram na espiga até o amadurecimento, quando foram coletados e mantidos em envelopes de papel à temperatura ambiente.

\section{RESULTADOS E DISCUSSÃO}

A eficiência da polinização (Tabela 1) determinada pelo número de grãos formados a partir do número de flores polinizadas, estimou a fertilidade nas progênies dos retrocruzamentos. No primeiro retrocruzamento (PF 839197/PF 84001//PF 839197), 368 flores foram polinizadas, com a formação de 22 grãos, o que equivale dizer que a fertilidade, neste primeiro retrocruzamento $(\mathrm{RC} 1)$ foi de $6.0 \%$. No segundo, (RC2) a formação de 24 grãos a partir de 194 flores polinizadas indicou um percentual de fertilidade de $12,4 \%$. As percentagens de formação de grãos no RC1-F1 e RC2-F1 observadas neste estudo demonstram que os resultados foram superiores aos obtidos em F1 por Comeau et al. (1985), 2,3\%; Limin \& Fowler (1990), 5,2 - 2,9 - 0,7 e 0\%; Plourde et al. (1990), 0,45\%; Chen et al. (1990), 0,41 a 2,87\%; Sharma \& Ohm (1990), 3,7\%; Chen et al. (1992), 2, 1\% ; e Franke (1992), 1,5\% em RCl.
Chen et al. (1992), em estudo sobre a análise citogenética de plantas das gerações RC1, RC2 e RC3 provenientes de cruzamentos entre T. aestivum e A. cristatum, obtiveram aumento de $7,32 \%$ na formação de sementes da geração RC1 para a RC2, e de $30 \%$ da geração $\mathrm{RC} 2$ para a $\mathrm{RC} 3$. A recuperação da fertilidade supõe-se estar relacionada à recuperação do genoma do trigo após cada retrocruzamento, fazendo com que o comportamento meiótico, na formação das células gaméticas, apresente menos anormalidades e produza uma maior proporção de óvulos e grãos de pólen viáveis. Em um processo normal de polinização, o grão de pólen adere ao estigma e, após sua hidratação, inicia-se a atividade metabólica com a germinação do tubo polínico. No caso de genitores totalmente incompatíveis, a reação da calose na superfície do estigma e a formação de tubos polínicos distorcidos revelam a ocorrência de uma barreira prézigótica (Dumas \& Knox, 1983, citados por Kerlan et al., 1992). A escolha certa dos genitores é, sem dúvida, um dos fatores determinantes para o sucesso dos cruzamentos. Outros fatores podem ter contribuído ainda para os resultados obtidos nesse trabalho:

- compatibilidade parcial entre pólen e óvulo dos genitores: pois sabe-se que além das barreiras intergenéricas, as diferenças genotípicas entre cultivares interferem positiva ou negativamente na fertilidade (Mujeeb-Kazi \& Kimber, 1985; Baum et al., 1992; Kerlan et al., 1992);

- sistema de emasculação diferenciado: no presente estudo, não houve o corte da ponta das glumas do parental feminino. Esse corte é um procedimento padrão em polinizações artificiais, porém pode levar à desidratação do estigma, antes ou após a polinização, inviabilizando a produção de sementes. Se-

TABELA 1. Eficiência da polinização na obtenção do RC1 e RC2 de cruzamentos intergenéricos entre Triticum aestivum e Agropyron elongatum.

\begin{tabular}{lccc}
\hline Retrocruzamento & $\begin{array}{c}\text { Flores polinizadas } \\
\left(\mathrm{n}^{\mathrm{o}}\right)\end{array}$ & $\begin{array}{c}\text { Grãos obtidos } \\
\left(\mathrm{n}^{\mathbf{0}}\right)\end{array}$ & $\begin{array}{c}\text { Fertilização } \\
(\%)\end{array}$ \\
\hline RC1 (PF 839197 / PF 84001 // PF 839197) & 368 & 22 & 6,0 \\
$\mathrm{RC2}$ (PF 839197 / PF 84001 // 2* PF 839197) & 194 & 24 & 12,4 \\
\hline Total & 562 & 46 & - \\
\hline
\end{tabular}


gundo Mujeeb-Kazi \& Kimber (1985), a desidratação do estigma em ambientes secos e com alta temperatura pode ser o maior obstáculo ao cruzamento com algumas espécies selvagens.

- procedimento de repolinização: caracteristicamente, o estigma do grupo de espécies, utilizado neste estudo indica a receptividade para a polinização por uma rápida elongação das células, produzindo uma aparência plumosa. A polinização geralmente é feita nesse momento. Polinizando o estigma antes das indicações morfológicas de receptividade, Mujeeb-Kazi et al. (1984) e Mujeeb-Kazi \& Kimber (1985) obtiveram maior formação de grãos híbridos, pois tal procedimento pôde evitar as barreiras à fertilização que ocorrem em estigmas maduros. A polinização nos retrocruzamentos, foi efetuada durante e após o período de estigma maduro, possivelmente colaborando na superação das barreiras prézigóticas de fertilização.

Todas as plantas híbridas oriundas do cruzamento inicial e do RC1 foram obtidas pelo resgate e cultivo in vitro dos embriões imaturos, antes da degeneração do endosperma. Observou-se que o endosperma dos grãos do RC1 apresentou aspecto aqüoso e hialino, com variações na quantidade e densidade. Dos 22 grãos coletados no RC1, 18 (81,7\%) embriões foram resgatados, dando origem a 12 plântulas (Tabela 2). A eficiência da cultura de embriões híbridos imaturos foi de $66,6 \%$, considerada alta para cruzamentos intergenéricos com Agropyron sp., quando comparada com os resultados obtidos por Mujeeb-Kazi et al., (1984), de 9,3 a 48\%; Comeau et al. (1985), 50 a 54\%; Chen et al. (1990), 30\%; Chen et al. (1992), 21\%; Plourde et al. (1990), 100 a 0\%; e Limin \& Fowler (1990), 6,5 - 4,5 e 50\%. Esse resultado indica que a técnica de resgate e o meio de cultura utilizado foram eficientes para o cultivo e a regeneração dos embriões híbridos. Quanto à técnica de resgate, certos procedimentos podem justificar o resultado obtido. Durante a extração dos embriões, por causa da câmara de fluxo laminar e da luz do estereomicroscópio, eles sofreram um rápido processo de desidratação. Para evitar danos nos tecidos, após serem corretamente dispostos no meio de cultura, os embriões foram reidratados com uma gota de água destilada esterilizada.

O período entre a polinização e a coleta dos embriões variou de 14 a 34 dias. Esse resultado corrobora as observações feitas por Brove et al. (1982), citados por Pasqual \& Pinto (1990).

Os dados referentes ao aspecto e desenvolvimento dos embriões são apresentados na Tabela 2. Dos 18 embriões resgatados, $50 \%$ tiveram aspecto e tamanho normal (aproximadamente $1 \mathrm{~mm}$ ), semelhantes a um embrião proveniente de autofecundação em trigo. Cinco embriões apresentaram forma normal, porém em tamanho reduzido (menos de $1 \mathrm{~mm}$ ). Três embriões foram deformados, o que impossibilitou a identificação do escutelo e da coleorriza, e um apresentou-se em estádio de desenvolvimento precoce, denominado jovem. Ao contrário das observações de Mujeeb-Kazi \& Kimber (1985), 50\% dos embriões resgatados apresentaram aspecto normal. Do total de plantas adultas regeneradas da cultura dos embriões, $72,7 \%$ originaram-se de embriões normais, $18,2 \%$ de embriões pequenos, e $9,1 \%$ de embriões

TABELA 2. Aspecto e desenvolvimento dos embriões resgatados e cultivados em meio de cultura, obtidos no RC1-F1 de cruzamentos entre Triticum aestivum e Agropyron elongatum ${ }^{\text {. }}$

\begin{tabular}{lcccccc}
\hline Aspecto & ER & EG & ED & MC & PR & PA \\
\hline Normais & 9 & 9 & 1 & 0 & 8 & 8 \\
Pequenos & 5 & 5 & 2 & 0 & 3 & 2 \\
Jovens & 1 & 1 & 1 & 0 & 0 & 0 \\
Deformados & 3 & 3 & 1 & 1 & 1 & 1 \\
\hline Total & 18 & 18 & 5 & 1 & 12 & 11 \\
\hline
\end{tabular}

${ }^{1}$ ER: embriões resgatados; EG: embriões germinados; ED: embriões degenerados; MC: embriões mortos por contaminantes; PR: plântulas regeneradas; PA: plantas adultas. 
deformados. Como pode-se verificar na Tabela 2, no total, a germinação dos embriões resgatados foi de $100 \%$. Deste total, apenas $27,7 \%$ degeneraram e $5,5 \%$ foram contaminados. Obteve-se, portanto, $66,6 \%$ de plântulas regeneradas e $61,1 \%$ de plantas adultas. Embora 50\% dos embriões tenham apresentado aspecto anormal, esta condição não foi obstáculo à germinação. Entre os embriões deformados, $33 \%$ foram eliminados por contaminantes. O embrião jovem entrou em processo de degeneração (necrose do tecido embrionário). Resultado semelhante foi descrito por Baum et al. (1992). Uma hipótese que pode explicar o êxito na germinação dos embriões é a eficiência do tratamento com frio pós-cultura, aplicado nos embriões resgatados. Sharma \& Ohm (1990) relataram um aumento de $12,5 \%$ na germinação de embriões híbridos expostos ao tratamento com frio. De acordo com revisão do mesmo autor, o efeito favorável desse tipo de tratamento na germinação dos embriões híbridos imaturos é similar ao que acontece em sementes maduras de trigo. O efeito do précondicionamento do embrião, antes de expô-lo à temperatura ideal para germinação, pode auxiliar na quebra de dormência, além de, lentamente, adaptá-lo ao meio de cultura prevenindo uma germinação precoce, que originaria plântulas sem vigor. Tal efeito é novamente mencionado em recente revisão de Sharma(1995).

O processo de aclimatação das plântulas regeneradas no tubo de ensaio levou em média 31 dias, variando entre 14 a 73 dias. Das plântulas regeneradas, $91,7 \%$ desenvolveram-se até a fase adulta.

No RC2 foi observado que o endosperma permaneceu viável, com capacidade de manter o grão íntegro na espiga até a fase final de amadurecimento. Dos 24 grãos formados no RC2, nenhum apresentou sinais de degeneração, originando sementes que atingiram a maturação fisiológica. Portanto, para a produção do RC2 não foi necessário o resgate dos embriões.

\section{CONCLUSÕES}

1. A obtenção de híbridos entre Triticum aestivum (PF 839197) e Agropyron elongatum (PF 84001) é viável quando utilizada a técnica de cultura de embriões imaturos.
2. O emprego do meio de cultura Batata-Regeneração modificado com vitaminas é eficiente na cultura dos embriões híbridos imaturos derivados da geração RC1-F1 dos cruzamentos entre Triticum aestivum (PF 839197) e Agropyron elongatum (PF 84001).

3. A geração RC2 dos cruzamentos entre Triticum aestivum (PF 839197) e Agropyron elongatum (PF 84001) pode ser obtida sem a cultura dos embriões.

\section{REFERÊNCIAS}

BAUM, M.; LAGUDAH, E.S.; APPLES, R. Wide crosses in cereals. Annual Review of Plant Physiology and Plant Molecular Biology, v.43, p.117-143, 1992.

CAUDERON, Y. Cytogenetics in breeding programes dealing with polyploidy, interespecific hybridization and introgression. In: HORN, JENSEN, ODENBACH, SCHIEDER (Eds.). Genetic manipulation in plant breeding. New York, 1986. p.83-104.

CHEN, Q.; JAHIER, J.; CAUDERON, Y. Intergeneric hybrids between Triticum aestivum and three crested wheatgrasses: Agropyron mongolicum, A. michnoi and $A$. desertorum. Genome, v.33, p.663-667, 1990.

CHEN, Q.; JAHIER, J.; CAUDERON, Y. Cytogenetic analysis of $\mathrm{BC} 1, \mathrm{BC} 2$ and $\mathrm{BC} 3$ progenies of an intergeneric hybrid between Triticum aestivum (L.) Thell and tetraploid Agropyron cristatum (L.) Gaertn. Theoretical and Applied Genetics, v.84, p.698-703, 1992.

CHUANG, C.-C.; OUYANG, T.W.; CHIA, H.; COUS, S.; CHING, C.K. A set of potato media for wheat anther culture. In: SYMPOSIUM ON PLANT TISSUE CUlTURE. Proceedings... Peking: Academy of Science Press, 1978. p.51-56.

COMEAU, A.; FEDAK, G.; St. PIERRE, C.A.; THERIAULT, C. Intergeneric Hybrids between Triticum aestivum and species Agropyron and Elymus. Cereal Research Communications, v.13, n.2/3, p.149-153, 1985.

FRANKE, R. Intergeneric hybrids between Triticum aestivum L. and wild Triticeae. Hereditas, v.116, p.225-231, 1992.

GRATTAPAGLiA, D.; MACHADO, M.A. Micropropagação. In: TORRES, A.C.; CALDAS, L.S. 
(Eds.). Técnicas e aplicações da cultura de tecidos de plantas. Brasília: ABCTP/Embrapa-CNPH, 1990. p.148-149.

HADLEY, H.H.; OPENSHAW, S.J. Interespecific and intergeneric hybridization. In: FEHR, W.R.; HADLEY, H.H. (Eds.). Hybridization of Crop Plants. Wisconsin: USA, 1980. Ch.7, p.135-141.

HOAGLAND, D.R.; ARNON, D.I. Hoagland solution. In: TUITE, J. (Ed.). Plant Pathological Methods I. Minnesota: Burgess Pub. Co. Minnesota, 1969. p.57-81.

JAUHAR, P.P. Alien gene transfer and genetic enrichment of bread wheat. In: DAMANIA, A.B. (Ed.). Biodiversity and wheat improvement. Mexico: A Wiley-Sayce, 1993. p.103-104.

JAUHAR, P.P. Meiosis and fertility of F1 hybrids between hexaploid bread wheat and decaploid tall wheatgrass (Thinopyrum ponticum). Theoretical and Applied Genetics, v.90, p.865-871, 1995.

KERLAN, M.C.; CHEVRE, A.M.; EBER, F.; BARANGER, A.; RENARD, M. Risk assessament of outcrossing of transgenic rapeseed to related species. I. Interespecific hybrid production under optimal conditions with emphasis on pollination and fertilization. Euphytica, v.62, p.145-153, 1992.

LIMIN, A.E.; FOWLER, D.B. An interespecific and amphiploid produced from Triticum aestivum crosses with Agropyron cristatum and A. desertorum. Genome, v.33 p.581-584, 1990.

MUJEEB-KAZI, A.; KIMBER, G. The Production, cytology and practibility of wide hybrids in the Triticeae. Cereal Research Communications, v.13, n.2/3, p.11-24, 1985.

MUJEEB-KAZI, A.; ROLDAN, S.; MIRANDA, J.L. Intergeneric hybrids of Triticum aestivum $\mathrm{L}$. with
Agropyron and Elymus species. Cereal Research Communications, v.12, n.1/2, p.75-79, 1984.

PASQUAL, M.; PINTO, J.E.B. Cultura de embriões. ABCTP Notícias, Brasília, n. 15, p.2-12, 1990.

PLOURDE, A.; FEDAK, G.; St. PIERRE, C.A.; COMEAU, A. A novel intergeneric hybrid in the Triticeae: Triticum aestivum x Psathyrostachys juncea. Theoretical and Applied Genetics, v.79, p.45-48, 1990.

RILEY, R.; KIMBER, G. The transfer of alien genetic variation to wheat. Annual Report of Plant Breeding Institute (1964-1965). Cambridge, p.6-63, 1966.

SHARMA, H.C. How wide can a wide cross be? Euphytica, v.82, p.43-64, 1995.

SHARMA, H.C.; GILL, B.S. New hybrids between Agropyron and wheat. II. Production, morphology and cytogenetic analysis of $\mathrm{F}_{1}$ hybrids and back cross derivatives. Theoretical and Applied Genetics, v.66, p.111-121, 1983.

SHARMA, H.C.; OHM, H.W. Crossability and embryo rescue enhacement in wide crosses between wheat and three Agropyron species. Euphytica, v.49, p.209-214, 1990.

SINGH, H.; PANNU, P.P.S.; DHALIWAL, H.S. Evaluation of perennial Triticeae for reistance to rusts and powdery mildew diseases of wheat. Plant Resourses Newsletter, v.93, p.40-42, 1993.

XUEYONG, Z.; ZHENSHENG, L.; SHUYANG, C. Production and identification of three $4 \mathrm{Ag}$ (4D) substitution lines of Triticum aestivum-Agropyron: relative transmission rate of alien chromosomes. Theoretical and Applied Genetics, v.83, p.707714, 1992. 